\title{
Exubera $^{\circledR}$ (inhaled insulin): an evidence-based review of its effectiveness in the management of diabetes
}

\author{
Louise Profit
}

Core Medical Publishing, Knutsford, UK

\begin{abstract}
Introduction: Inadequate glycemic control contributes to the development and progression of complications, which are associated with a significant economic burden on healthcare systems. However, optimal glycemic control is difficult to sustain with oral antidiabetic agents and adherence to intensive insulin regimens is compromised by patient compliance to multiple daily injections. Therefore, alternative delivery systems are required to improve the acceptability of insulin therapy.
\end{abstract}

Aims: This review assesses the evidence for the therapeutic value of inhaled insulin (Exubera ${ }^{\circledR}$ ) in the management of type 1 and type 2 diabetes.

Evidence review: Evidence indicates that glycemic control, as measured by plasma $\mathrm{HbA}_{1 \mathrm{c}}$ levels, with Exubera is as effective as subcutaneous insulin in patients with type 1 or type 2 diabetes. There is also good evidence that Exubera provides improved patient satisfaction and ease of use compared with subcutaneous insulin. However, the cost effectiveness of Exubera and its place in therapy compared with other inhaled insulin delivery systems currently in development remain to be determined.

Outcomes summary: Exubera is an alternative treatment option for the management of diabetes which provides effective glycemic control with improved patient satisfaction.

Key words: inhaled insulin, type 1 diabetes, type 2 diabetes, glycemic control, evidence, outcomes

\section{Core evidence outcomes summary for Exubera (inhaled insulin) in the management of type 1 and type 2 diabetes}

\begin{tabular}{|lll|}
\hline Outcome measure & Evidence & Implications \\
\hline Patient-oriented evidence & & \\
Improved patient satisfaction & Clear & Improved preference for Exubera compared with subcutaneous insulin \\
No significant weight gain & Clear & Similar to or less than subcutaneous insulin \\
Improvement in quality of life & Moderate & Improved quality of life with Exubera compared with subcutaneous insulin \\
Disease-oriented evidence & & \\
Effective glycemic control - reduction in $\mathrm{HbA}_{1 \mathrm{C}}$ levels & Clear & Exubera is as effective as subcutaneous insulin \\
Incidence of hypoglycemia & Moderate & Similar to subcutaneous insulin \\
Reduction in pulmonary function & Limited & No clinically relevant effect in short term; long-term studies not published \\
Economic evidence & & \\
Cost effectiveness in patients with type 1 and type 2 diabetes & No evidence & Remains to be determined \\
\hline
\end{tabular}




\section{Scope, aims, and objectives}

Effective glycemic control is associated with a reduced risk of microvascular and macrovascular complications in patients with diabetes. The inconvenience and poor patient acceptability of intensive insulin regimens, which may require several injections per day, has contributed to poor glycemic control in patients with type 1 or type 2 diabetes. Therefore, alternative routes of insulin administration to achieve and maintain optimal glycemic control have been investigated. A dry-powder insulin has been developed for the pulmonary delivery of insulin by an aerosol device $\left(\right.$ Exubera $^{\circledR}$ ). The objective of this article is to review the current evidence for this insulin delivery system in the clinical management of type 1 and type 2 diabetes. To distinguish this insulin delivery system from others being developed, it is referred to as Exubera throughout.

\section{Methods}

Literature searches were conducted on January 17-26, 2005, in the following databases using the search terms "Exubera," "pulmonary insulin," OR "inhaled insulin." The cut-off date was from the beginning of the database to the date of the search unless otherwise stated:

- PubMed, http://www.ncbi.nlm.nih.gov/entrez/query.fcgi, 1966 to date. Search strategy: "Exubera OR inhaled insulin" limited to English-language results only

- EMBASE, http://www.datastarweb.com, 1974 to date. Search strategy: "Exubera OR inhaled insulin" limited to Englishlanguage results only

- Database of Abstracts of Reviews of Effectiveness (DARE), NHS Economic Evaluations Database (NHSEED), Health Technology Assessment (HTA), www.york.ac.uk/inst/crd/darehp.htm. All three databases were searched together. All fields searched

- National Guideline Clearing House, www.guideline.gov

- National Institute for Health and Clinical Excellence (NICE), www.nice.org.uk

- Cochrane Database of Systematic Reviews (CDSR), www.cochrane.org/index0.htm. Entire site searched

After removal of duplicates, a total of 206 records were retrieved, one from DARE and the remainder from PubMed or EMBASE. Clinical guidelines were also identified from NICE, the European Diabetes Policy Group (EDPG), and the American Diabetes Association (ADA). Records were manually reviewed and any animal studies, in-vitro studies, news articles, general narrative reviews, or articles which mentioned Exubera but did not discuss clinical trial data were excluded. The remaining 11 records were included.

Any identified systematic reviews (including meta analyses), randomized controlled trials (RCTs), and relevant case studies were then classified into five classes of evidence based on the
Table 1 | Evidence base included in the review

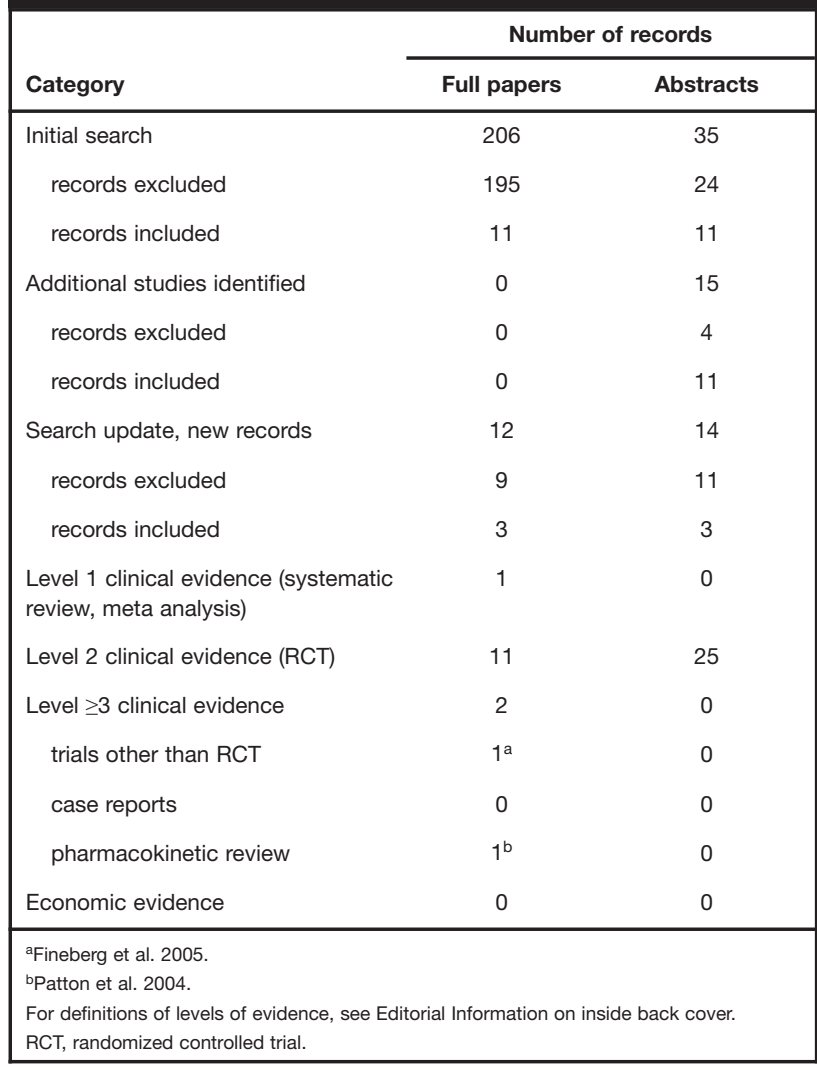

design of the study, with level 1 evidence representing the strongest level of evidence and level 5 representing the weakest evidence as summarized in Table 1. One systematic review was identified. All other articles were of level 2 or level 3 evidence reported as full publications. Publications relating to pharmacoeconomic evidence with Exubera were not identified.

Thirty-five abstracts from ADA meetings and European Association for the Study of Diabetes (EASD) meetings (1998-2003) were identified from a systematic review of these sources. Twenty-three abstracts were excluded because they were animal studies $(n=1)$ or were abstracts that duplicated results from studies which have since been published in full $(n=22)$. One abstract (level 3 evidence) which detailed results from a pooled analysis of two multicenter randomized controlled phase II trials in patients with type 1 and type 2 diabetes was also excluded due to the availability of significant level 2 evidence (Cappelleri et al. 2001).

Abstracts from the 64th Scientific Sessions of the ADA 2004 and the 40th EASD Meeting 2004 were also searched electronically on January 26-27, 2005, using the search terms "Exubera" OR "inhaled insulin." This yielded 15 records, of which four were excluded for the following reasons: animal studies $(n=2)$, duplicate publication of data presented in full papers $(n=2)$ (Table 1). All abstracts were of level 2 evidence. 
The searches were updated on June 23, 2005. After excluding duplicates, a total of 12 new records were identified, of which nine were excluded for the following reasons: general narrative reviews $(n=3)$, articles that did not mention Exubera $(n=5)$, animal study $(n=1)$. Three articles remained, and were included (Table 1). Abstracts from the 65th Scientific Sessions of the ADA 2005 (http://scientificsessions.diabetes.org) were also searched electronically on June 29, 2005. This yielded 14 records, of which 11 were excluded for the following reasons: did not refer to Exubera $(n=9)$, animal studies $(n=2)$ (Table 1). All abstracts were of level 2 evidence.

\section{Disease overview}

\section{The diabetes epidemic}

It is estimated that there are currently approximately 194 million people with diabetes worldwide and the prevalence is projected to exceed 333 million by 2025 (IDF 2005). Type 1 diabetes may account for $5-10 \%$ of all diagnosed cases of diabetes and usually affects children and young adults, although onset may occur at any age (ADA 2005a). In comparison, type 2 diabetes accounts for over $90 \%$ of diabetes cases and is associated with age, obesity, family history of diabetes, impaired glucose metabolism, physical inactivity, and race/ethnicity. The increasing prevalence of type 2 diabetes in children and adolescents is fast being recognized as a global health problem (Pinhas-Hamiel \& Zeitler 2005).

\section{Consequences of inadequate glycemic control}

A recent report by the American Association of Clinical Endocrinologists (AACE) highlighted that $67 \%$ of individuals with type 2 diabetes did not have adequately controlled blood glucose levels (AACE 2005). Uncontrolled diabetes may contribute to increased rates of macrovascular and microvascular diabetic complications. Indeed people with diabetes are two to four times more likely to develop cardiovascular disease and have a greater risk of heart attack or stroke than individuals without diabetes (IDF 2005). Diabetes is also the leading cause of end-stage renal disease, accounting for $44 \%$ of new cases and is the leading cause of blindness in the Western world (CDC 2003). These complications place a huge burden on healthcare services. It is estimated that the total direct and indirect expenditure for diabetes in the US alone in 2002 was $\$$ US132 billion (Hogan et al. 2003). A recent meta analysis of prospective cohort studies in patients with diabetes has also suggested that hyperglycemia is associated with an increased risk of cardiovascular disease (Selvin et al. 2004).

The UK Prospective Diabetes Study (UKPDS) and the Diabetes Control and Complications Trial (DCCT) demonstrated that the risk of developing and the progression of microvascular complications are substantially reduced with intensive blood glucose control $\left(\mathrm{HbA}_{1 \mathrm{c}}\right.$ approximately $\left.7 \%\right)$ in both type 2 diabetes (UKPDS 1998a,b) and type 1 diabetes (DCCT 1993). In general, for every $1 \%$ reduction in $\mathrm{HbA}_{1 \mathrm{c}}$, the risk of developing microvascular diabetic complications is reduced by $40 \%$ (CDC 2003). The DCCT study showed that intensive insulin therapy (administration of insulin three or more times daily by injection or an external pump) decreased the frequency and severity of microvascular and neurologic complications compared to conventional insulin (DCCT 1993). The occurrence of microalbuminuria was reduced by $39 \%$ and albuminuria and clinical neuropathy were reduced by $54 \%$ and $60 \%$, respectively. However, this intensive therapy was associated with a two- to three-fold increase in severe hypoglycemia. Furthermore, the UKPDS 33 study demonstrated that weight gain was significantly higher (mean $+2.9 \mathrm{~kg}$ ) in patients with type 2 diabetes receiving intensive blood glucose control with sulfonylureas or insulin compared with conventional treatment with diet $(P<0.001)$ (UKPDS 1998a). A further study in Japanese patients with type 2 diabetes demonstrated that intensive glycemic control by multiple insulin injection therapy delayed the onset and progression of diabetic retinopathy, nephropathy, and neuropathy more effectively than conventional insulin therapy (Ohkubo et al. 1995).

\section{Current therapy options}

\section{Type 1 diabetes}

Type 1 diabetes develops when the body's immune system destroys pancreatic beta cells and the individual is unable to produce insulin to control blood glucose levels. Therefore, it is essential that patients with type 1 diabetes receive insulin. Several types of human insulin and insulin analogs are currently available (Table 2). Insulin may be delivered by subcutaneous, multiple injections via a syringe or a pen with needle and cartridge, or via an insulin pump (ADA 2004). Insulin pumps are small devices (about the size of a pager), containing a reservoir of rapid-acting insulin, which are programmed to deliver a constant flow of insulin into the patient via a needle or cannula.

Rapid-acting insulin analogs are generally injected with a meal and have a rapid onset and a short duration of action, so there is less chance of hypoglycemia. These are generally considered the most

$\begin{aligned} & \text { Table } 2 \text { | Commonly used human and analog insulins (adapted } \\ & \text { from ADA 2005b) }\end{aligned}$
Rapid-acting insulin analogs
Insulin lispro (Humalog ${ }^{\circledR}$ )
Insulin aspart analog (Novolog ${ }^{\circledR}$ USA; NovoRapid ${ }^{\circledR}$ Europe)
Insulin glulisine (Apidra ${ }^{\text {TM}}$ )
Short-acting insulin
Human insulin (Humulin $\mathrm{R}^{\circledR} /$ Novolin $^{\circledR}$ )
Intermediate-acting insulin
Human NPH (Humulin $\mathrm{N}^{\circledR} / \mathrm{Novolin}^{\circledR}$ )
Lente
Long-acting insulin
Insulin glargine analog (Lantus ${ }^{\circledR}$ )
Human ultralente (Humulin U Ultralente ${ }^{\circledR}$ )
Insulin detemir (Levemir ${ }^{\circledR}$ ) - not yet approved in the USA


appropriate type of insulin for mealtime use. Short-acting insulins may also be used at mealtimes. However, their time to onset and duration of action is greater than that of the rapid-acting analogs. Long-acting insulins are the best options for basal control of blood glucose and are generally used in combination with either rapidacting or short-acting insulin. Premixed insulins are also available which contain a combination of intermediate-acting and either rapid-acting or short-acting insulins. These premixed insulins are generally available as pre-filled insulin pens which improve the accuracy of insulin administration and adherence.

One of the major disadvantages of insulin use is the occurrence of hypoglycemia resulting from an imbalance of insulin use, and physical activity and/or calorie consumption.

\section{Type 2 diabetes}

Initially, patients with type 2 diabetes may be able to control their blood glucose levels with diet and exercise alone or with antihyperglycemic drug monotherapy. However, many patients will progress to require additional therapies (combination oral agents and/or insulin). Currently, there are several classes of oral antidiabetic medication available which may be used as a monotherapy or in combination (Table 3). Most of the commonly used oral antidiabetics are only able to reduce $\mathrm{HbA}_{1 \mathrm{c}}$ by approximately $1 \%$. This reduction is not sufficient for patients who have $\mathrm{HbA}_{1 \mathrm{c}}$ levels much greater than the recommended target. Furthermore, long-term glycemic control is difficult to sustain with oral antidiabetic agents and many patients additionally require insulin therapy.

Table 3 | Oral antidiabetic medications used for the treatment of type 2 diabetes

Class and mechanism of action
Biguanides
Reduce hepatic glucose production
Stimulate the islet $\beta$ cells of the
pancreas to produce more insulin
first generation
second generation

Rapid-acting insulin secretagogs (meglitinides)

Stimulate glucose-mediated insulin secretion

$\alpha$-glucosidase inhibitors

Delay digestion and absorption of intestinal carbohydrate

Chlorpropamide, tolazamide

Glibenclamide (glyburide), glipizide, glimepiride, gliclazide, gliquidone

Nateglinide, repaglinide

\section{Acarbose, miglitol}

Thiazolidinediones (glitazones)

Peroxisome proliferator-activated receptor- $\gamma$ agonists: insulin sensitizer

improving insulin action and reducing insulin resistance
New classes of noninsulin diabetic drugs have entered the market to address the need for long-term glycemic control in patients with type 2 diabetes. These include the glucagon-like peptide-1 (GLP-1) agonist exenatide (Byetta ${ }^{\circledR}$ ), and a synthetic analog of human amylin called pramlintide acetate $\left(\right.$ Symlin $\left.{ }^{\circledR}\right)$ which was approved by the Food and Drug Administration (FDA) in March 2005. The dipeptidyl peptidase-4 (DPP-4) inhibitors are also soon expected to enter the market.

\section{GLP-1 analogs}

GLP-1 is an incretin hormone which is secreted from endocrine cells located in the intestinal mucosa, and acts to enhance mealinduced insulin secretion. GLP-1 analogs are injectable and it is expected that they will be used following the failure of oral antidiabetic agents in patients who are reluctant to use insulin. The GLP-1 analog exenatide is the first in a new class of diabetes treatment called incretin mimetics to be approved by the FDA (June 2005). It is approved as an adjunctive therapy in patients with type 2 diabetes who have not achieved adequate control on metformin and/or a sulfonylurea. Liraglutide, a long-acting derivative of GLP-1 which will be administered by injection once a day, is expected to be launched in 2007.

\section{DPP-4 inhibitors}

The DPP-4 inhibitors inhibit the enzyme responsible for the breakdown of GLP-1 (Nielsen 2005). In animal studies, DPP-4 inhibitors have been reported to suppress DPP-4 activity by up to $90 \%$ and to delay the onset of hyperglycemia (Nielsen 2005). Several DPP-4 inhibitors are currently in development including LAF-237 (Novartis) and MK-431 (Merck) (Barlocco 2004). These inhibitors are currently in phase III trials and the launch of LAF-237 and MK-431 are expected in 2007 and 2009, respectively. In contrast to the GLP-1 analogs, these agents will be available as oral formulations which should increase patient acceptability and compliance.

\section{Current treatment guidelines}

Recent US, European, and UK guidelines for type 2 diabetes recommend glycemic targets with an $\mathrm{HbA}_{1 \mathrm{c}}$ target range below 6.5-7.5\% (EDPG 1999; NICE 2002; ADA 2005c). The ADA guidelines also recommend considering a target of $<6 \%$ in individual patients (ADA 2005c). The risks and benefits of $\mathrm{HbA}_{1 \mathrm{c}}$ levels below $6 \%$ are currently being evaluated by the ongoing Action to Control Cardiovascular Risk in Diabetes (ACCORD) study in patients with type 2 diabetes.

Current NICE guidelines (due to be reviewed in September 2005) recommend that insulin therapy should be offered to diabetic patients with inadequate blood glucose control receiving optimized oral antidiabetic agents (NICE 2002). Furthermore, EDPG guidelines recommend that insulin therapy is initiated when $\mathrm{HbA}_{1 \mathrm{c}}$ has deteriorated to $>7.5 \%$ after maximum attention to dietary control and oral glucose-lowering therapy (EDPG 1999). An algorithm for the treatment of type 2 diabetes mellitus suggests that insulin should be reserved for patients who fail to 
Table 4 | Inhaled insulin products: delivery system and trial phase

\begin{tabular}{|c|c|c|c|}
\hline Inhaled insulin system & Manufacturer & Delivery system & Phase \\
\hline Exubera $^{\circledR}$ & $\begin{array}{l}\text { Pfizer; Sanofi-Aventis Group and } \\
\text { Nektar Therapeutics }\end{array}$ & $\begin{array}{l}\text { Fine dry-powder insulin } \\
\text { Air-assisted mechanism disperses the } \\
\text { powder from single-dose blisters into } \\
\text { a respirable cloud captured in a } \\
\text { holding chamber }\end{array}$ & $\begin{array}{l}\text { Phase III } \\
\text { Filed for approval in Europe } \\
\text { Recommended for approval in USA }\end{array}$ \\
\hline $\begin{array}{l}\text { AERx }{ }^{\circledR} \text { insulin Diabetes Management } \\
\text { System (iDMS) }\end{array}$ & Aradigm and Novo Nordisk & $\begin{array}{l}\text { Aqueous mist inhaler } \\
\text { Single-use insulin strips with a hand- } \\
\text { held, breath-activated, } \\
\text { microprocessor-controlled device }\end{array}$ & Phase III \\
\hline $\begin{array}{l}\text { Advanced Inhalation Research } \\
\text { (AIR) System }\end{array}$ & Alkermes and Eli Lilly \& Company & Breath-activated dry-powder inhaler & Entering phase III \\
\hline Technosphere Insulin System & MannKind Corporation & $\begin{array}{l}\text { Proprietary dry-powder technosphere } \\
\text { formulation } \\
\text { Inhaled using MedTone }{ }^{\circledR} \text { inhaler }\end{array}$ & Phase III \\
\hline Aerodose $^{\mathrm{TM}}$ & $\begin{array}{l}\text { Aerogen and Disetronic Medical } \\
\text { Systems }\end{array}$ & $\begin{array}{l}\text { Liquid insulin formulation (Humalin } \mathrm{I}^{\mathrm{TM}} \\
500 \text { units) } \\
\text { Aerosol delivered by a breath- } \\
\text { activated delivery device }\end{array}$ & Phase II \\
\hline Inhaled insulin & Kos Pharmaceuticals Inc. & Dry crystals propellant inhaler & Phase II \\
\hline Bio-Air & BioSante Pharmaceuticals & Coated dry particles & Preclinical \\
\hline
\end{tabular}

adequately respond to a combination of oral antidiabetic agents (Krentz \& Bailey 2005). However, Krentz and Bailey (2005) suggest that prescribing decisions often appear to be made on subjective grounds such as familiarity with a particular drug which may explain regional differences in prescribing.

\section{Unmet needs}

To avoid the development of complications and reduce morbidity and mortality in patients with diabetes, tight glycemic control is of great importance. Insulin therapy is central to the treatment of patients with type 1 diabetes. In contrast, the progressive decrease in beta-cell function in the pathogenesis of type 2 diabetes means that many patients will eventually fail on oral antidiabetic agents and will require insulin. It is well known in routine clinical practice that the majority of patients fail to achieve optimal glycemic control. Data from the National Health and Nutrition Examination Survey (NHANES) III demonstrated that from 1988 to 2000 a decrease in glycemic control was observed among US adults diagnosed with type 2 diabetes (Koro et al. 2004). The proportion of patients with $\mathrm{HbA}_{1 \mathrm{c}}$ levels $<7 \%$ declined from $44.5 \%$ in the period $1988-1994$ to $35.8 \%$ between 1999 and 2000. The use of insulin alone also decreased from $24.2 \%$ to $16.4 \%$ in these periods. There is reluctance by patients and physicians to treat type 2 diabetes with insulin despite its ability to achieve tight glycemic control. Healthcare providers often delay the initiation and intensification of insulin therapy in patients with type 2 diabetes until after the failure of multiple oral agents. This reluctance to initiate insulin therapy is partly due to the burden of multiple daily injections which are associated with poor patient compliance, particularly in those patients with a phobia of needles, and a fear of causing hypoglycemia or weight gain
(Korytkowski 2002). Therefore, alternative insulin delivery systems are required to improve patient and physician acceptability, adherence with insulin therapy, and thus improve the management of the disease. However, the mode of administration may not be the only issue. Many patients may perceive insulin per se as a "failure" in themselves or their health professional and that their diabetes is now "severe."

New methods for the delivery of insulin must balance improved patient acceptability, convenience and quality of life with achievement of therapeutic drug levels that are at least as effective as traditional subcutaneous formulations on diabetic outcomes such as blood glucose and $\mathrm{HbA}_{1 \mathrm{c}}$, without increasing the risk of hypoglycemic episodes or weight gain. It is expected that improved glucose control achieved by better adherence to insulin regimens will reduce the development of complications commonly associated with diabetes.

Advances in syringe and needle technology and the use of insulin pens and pumps have improved the accuracy and convenience of insulin administration. Despite the relative success of these devices, several different routes of administration have been investigated including the transdermal, intranasal, oral, buccal, and pulmonary routes (Owens et al. 2003; Cefalu 2004). Limited success has been achieved with intranasal, oral, and transdermal insulin delivery. Due to the large size of the insulin molecule, nasal and transdermal delivery is inadequate and requires penetration enhancers which pose safety concerns (Owens et al. 2003; Cefalu 2004). Therefore, these modes of delivery would be more suited to basal administration of insulin. Oral enteric insulin is broken down by digestive enzymes and has limited bioavailability (Cefalu 2004). A buccal system (Oralin) delivering a liquid formulation of 
insulin as a fine spray via the Generex Rapid Mist ${ }^{\mathrm{TM}}$ device has been developed by Generex Biotechnology. Limited data in patients with type 2 diabetes have demonstrated that Oralin may be used instead of meal-time insulin injections (Guevara-Aguirre et al. 2004a,b).

The lungs have a large surface area, highly permeable membrane, and rich blood perfusion offering great potential for the delivery of polypeptide drugs such as insulin across the alveolar wall. Several inhaled insulin products have been successful in controlling blood glucose levels and three products are currently in phase III clinical trials (Table 4). Comparisons between these inhaled insulin delivery systems are needed to determine the advantages and disadvantages of each system including their relative convenience and ease of use.

Of these different inhaled insulin products, Exubera is the furthest along in development. Exubera is a fine dry-powder (particle size 1-5 $\mu \mathrm{m}$ ) insulin formulation jointly developed by Pfizer and SanofiAventis Group. The insulin formulation developed by Nektar Therapeutics is packaged into blisters containing either 1 or $3 \mathrm{mg}$ of insulin and made up to a total weight of $5 \mathrm{mg}$ with mannitol, glycine, and sodium citrate. Higher doses are achieved with further inhalation of 1 or $3 \mathrm{mg}$ blisters. Nektar Therapeutics developed both the insulin blisters and a hand-held inhaler device, which converts the powder particles into an aerosol cloud. This noninvasive, pulmonary inhalation system delivers insulin into the systemic circulation via the lung alveoli by transcytosis. No power source or propellants are used and the clear chamber ensures that the patient knows when all the insulin has been inhaled to allow accurate dosing. However, some patients may question the convenience of the chamber with regards to its portability.

The AERx ${ }^{\circledR}$ iDMS delivery device includes a breath-guidance system that only delivers drug to the lung when breathing is correct (Mandal 2005). This device also features a datadownloading system, facilitating the review of dose administration data and breathing technique. This provides clinicians with information about patient dosing regimens and compliance (Cramer et al. 2004). In comparison, the Technosphere insulin system used a commercially available asthma inhaler for the proof-of-concept study (Steiner et al. 2002).

\section{Clinical evidence with Exubera}

A number of patient- and disease-oriented outcomes have been evaluated with Exubera that reflect its potential role in the management of diabetes. Fundamentally, the formulation must demonstrate that therapeutic levels of insulin can be achieved, which have an effect on blood measures of glucose and which do not raise the risk of hypoglycemia. From a patient perspective, the formulation needs to be acceptable to patients and ideally more convenient than alternative methods of delivery.

\section{Achievement of insulin levels}

Studies assessing the pharmacokinetics of Exubera in healthy volunteers and in patients with type 2 diabetes have shown that Exubera is rapidly absorbed, with insulin concentrations peaking earlier and decreasing more rapidly compared with subcutaneous regular insulin (Patton et al. 2004). Furthermore, the onset of action (time to maximal effect) of Exubera has been shown to be at least as fast as the subcutaneously injected rapid-acting insulin analog insulin lispro in healthy volunteers (143 min versus $137 \mathrm{~min}$ ) (Rave et al. 2005). The duration of action, as determined by time to late half-maximal effect, was longer with Exubera than lispro (387 min versus $313 \mathrm{~min}$ ). These characteristics suggest that Exubera provides an alternative therapy for meal-time glucose control.

\section{Blood glucose control}

The efficacy of Exubera was primarily assessed by equivalence studies comparing glycemic control with subcutaneous insulin. Reduction in $\mathrm{HbA}_{1 \mathrm{c}}$ levels and the proportion of patients who met treatment guideline targets for $\mathrm{HbA}_{1 \mathrm{c}}$ (i.e. below 6.5-7.5\%) were the main outcomes for efficacy.

Strong level 1 evidence from a systematic review of small, shortterm, proof of concept phase II studies in patients with type 1 diabetes (3 studies) and type 2 diabetes (3 studies) showed similar $\mathrm{HbA}_{1 \mathrm{c}}$ reductions in patients randomized to inhaled insulin

Table 5 | Level 2 evidence of blood glucose control in patients with type 1 diabetes achieved with Exubera compared with conventional insulin regimens. Both studies were open-label, randomized, multicenter design lasting 24 weeks

\begin{tabular}{|c|c|c|c|}
\hline \multirow[t]{2}{*}{ Study } & \multirow[t]{2}{*}{ Treatment group } & \multicolumn{2}{|c|}{ Outcome } \\
\hline & & Mean reduction in $\mathrm{HbA}_{1 \mathrm{c}}(\%)$ & $\%$ patients with $\mathrm{HbA}_{1 \mathrm{c}}<7 \%$ \\
\hline \multirow[t]{2}{*}{ Skyler et al. 2005} & $\begin{array}{l}\text { Exubera (premeal) plus morning and evening NPH insulin } \\
(\mathrm{n}=163)\end{array}$ & 0.3 & 23.3 \\
\hline & $\begin{array}{l}\text { Regular s.c. insulin (premeal) plus morning and evening } \\
\text { NPH insulin }(n=165)\end{array}$ & 0.1 & 22 \\
\hline \multirow[t]{2}{*}{ Quattrin et al. 2004} & $\begin{array}{l}\text { Exubera (premeal) plus a single bedtime ultralente s.c. } \\
\text { injection }(n=170)\end{array}$ & 0.2 & 15.9 \\
\hline & $\begin{array}{l}\text { Two to three s.c. injections of regular and NPH insulin } \\
(n=164)\end{array}$ & 0.4 & 15.5 \\
\hline
\end{tabular}


Table 6 | Level 2 evidence of blood glucose control in patients with type 2 diabetes achieved with Exubera compared with conventional insulin regimens. All studies were open-label, randomized, parallel-group, multicenter design

\begin{tabular}{|c|c|c|c|c|c|}
\hline \multirow[t]{2}{*}{ Study } & \multirow[t]{2}{*}{ Treatment group } & \multirow[t]{2}{*}{ Study design } & \multicolumn{3}{|c|}{ Outcome } \\
\hline & & & $\begin{array}{l}\text { Mean reduction } \\
\text { in } \mathrm{HbA}_{1 \mathrm{c}}(\%)\end{array}$ & $\begin{array}{l}\% \text { patients with } \\
\mathrm{HbA}_{1 \mathrm{c}}<7 \% \text { (ADA) }\end{array}$ & $\begin{array}{l}\% \text { patients with } \\
\mathrm{HbA}_{1 \mathrm{c}}<6.5 \% \\
\text { (EDPG) }\end{array}$ \\
\hline \multirow[t]{2}{*}{ Hollander et al. 2004} & $\begin{array}{l}\text { Exubera (premeal) plus bedtime } \\
\text { dose of ultralente }(n=149)\end{array}$ & $\begin{array}{l}24 \text { weeks; patients previously } \\
\text { treated with insulin }\end{array}$ & 0.7 & 46.9 & 28.7 \\
\hline & $\begin{array}{l}\geq 2 \text { daily injections of s.c. insulin } \\
\text { (mixed regular/NPH insulin; } n=150 \text { ) }\end{array}$ & & 0.6 & 31.7 & 17.2 \\
\hline \multirow[t]{3}{*}{$\begin{array}{l}\text { Rosenstock et al. 2002; } \\
\text { Cefalu } 2002\end{array}$} & $\begin{array}{l}\text { Exubera (premeal) monotherapy } \\
(\mathrm{n}=105)\end{array}$ & $\begin{array}{l}12 \text { weeks; patients failing on } \\
\text { combination oral antidiabetic } \\
\text { agents (sulfonylurea or repaglinide, } \\
\text { plus metformin or a glitazone) }\end{array}$ & 1.4 & 16.7 & 12.2 \\
\hline & $\begin{array}{l}\text { Exubera plus existing oral } \\
\text { antidiabetic medication }(n=102)\end{array}$ & & 1.9 & 32 & 7.8 \\
\hline & $\begin{array}{l}\text { Continued oral antidiabetic } \\
\text { medication }(n=102)\end{array}$ & & 0.2 & 1 & 0 \\
\hline \multirow[t]{2}{*}{$\begin{array}{l}\text { Bergenstal et al. 2003; } \\
\text { DeFronzo } 2003\end{array}$} & $\begin{array}{l}\text { Exubera (premeal) monotherapy } \\
(\mathrm{n}=76)\end{array}$ & $\begin{array}{l}12 \text { weeks; patients failing on diet } \\
\text { and exercise alone }\end{array}$ & 2.3 & 44 & 28 \\
\hline & $\begin{array}{l}\text { Rosiglitazone } 4 \text { mg twice daily } \\
(n=69)\end{array}$ & & 1.4 & 17.9 & 7.5 \\
\hline \multirow[t]{4}{*}{ Barnett 2004} & \multirow[t]{2}{*}{ Adjunctive Exubera $(n=471)$} & \multirow{4}{*}{$\begin{array}{l}\text { Open-label, } 24 \text { weeks extended to } \\
52 \text { weeks; patients poorly } \\
\text { controlled by metformin or } \\
\text { sulfonylurea }\left(\mathrm{HbA}_{1 \mathrm{c}} \geq 8 \%\right)\end{array}$} & $2.2 \%$ (week 24) & ND & ND \\
\hline & & & $2 \%$ (week 52) & & \\
\hline & \multirow{2}{*}{$\begin{array}{l}\text { Additional oral antidiabetic } \\
\text { (metformin or glibenclamide) } \\
(\mathrm{n}=441)\end{array}$} & & $2.2 \%$ (week 24) & ND & ND \\
\hline & & & $1.8 \%$ (week 52) & & \\
\hline \multirow[t]{2}{*}{ Dreyer 2004} & Adjunctive Exubera $(n=471)$ & $\begin{array}{l}24 \text { weeks, extended to } 104 \text { weeks; } \\
\text { patients poorly controlled by } \\
\text { metformin or sulfonylurea } \\
\left(\mathrm{HbA}_{1 \mathrm{c}} \geq 8 \%\right)\end{array}$ & $1.9 \%$ & ND & ND \\
\hline & $\begin{array}{l}\text { Additional oral antidiabetic } \\
\text { (metformin or glibenclamide) } \\
(\mathrm{n}=441)\end{array}$ & & $1.5 \%$ & ND & ND \\
\hline
\end{tabular}

plus subcutaneous ultralente compared with a control group who received their former subcutaneous insulin regimen (Cefalu et al. 2001; Skyler et al. 2001; Royle et al. 2003). A further proof of concept superiority study also showed that glycemic control could be improved in insulin-naïve patients with type 2 diabetes and suboptimal glycemic control by the addition of Exubera to oral antidiabetic agents compared to oral antidiabetic monotherapy (Weiss et al. 2003).

These observations are supported by evidence from two openlabel, randomized phase III clinical studies of 6 months' duration which demonstrates that Exubera provides glycemic control comparable to that with conventional insulin regimens in patients with type 1 diabetes (Quattrin et al. 2004; Skyler et al. 2005) (Table 5). Furthermore, a study in 226 patients with type 1 diabetes has shown that Exubera provides glycemic control similar to that of a subcutaneous short-acting insulin over a 12week period (Dumas et al. 2005a).
Results from three open-label, randomized, parallel-group, multicenter, phase III clinical trials in patients with type 2 diabetes have also demonstrated comparable reductions in $\mathrm{HbA}_{1 \mathrm{c}}$ between Exubera and conventional subcutaneous insulin regimens (Hollander et al. 2004). Furthermore, superiority studies showed that Exubera either alone or in combination with oral antidiabetic regimens demonstrated improved glycemic control compared with oral agent monotherapy (Cefalu 2002; Rosenstock 2002; Bergenstal 2003; DeFronzo 2003; Barnett 2004; Dreyer 2004) (Table 6). Moreover, more patients with type 2 diabetes who were treated with inhaled insulin achieved the ADA and EDPG (IDF Region) targets for $\mathrm{HbA}_{1 \mathrm{c}}$ levels compared with other regimens (Table 6) (Bergenstal 2004).

In all the phase III trials comparing Exubera with subcutaneous insulin, the control groups had two or more insulin injections daily of a soluble insulin, in addition to a basal insulin. However, only one study (Skyler et al. 2005) used the same basal insulin in both 
treatment groups, and none of the studies used a short-acting insulin analog.

\section{Patient satisfaction}

Eight clinical trials evaluated treatment satisfaction and quality of life compared with subcutaneous insulin or oral antidiabetic therapy in both patients with type 1 diabetes (Gerber et al. 2001; Testa et al. 2001a,b; Quattrin et al. 2004) and type 2 diabetes (Simonson et al. 2001, 2004; Cappelleri et al. 2002; Testa et al. 2002, 2004a,b; Hollander et al. 2004) (Table 7).

In general, inhaled insulin had a greater acceptance relating to convenience and ease of use. For obvious practical reasons, these studies were unblinded to their intervention which could potentially affect the outcomes. Furthermore, in these studies patients used syringes and standard needles which are less convenient and more painful than pen-injector devices. The majority of these studies were conducted in the USA, where insulin pen-injector devices are not approved. Therefore, further studies are required to compare treatment satisfaction with inhaled insulin versus pen-injector devices. Patient satisfaction was assessed using a self-administered satisfaction questionnaire. The Patient Satisfaction with Insulin Therapy (PSIT) questionnaire was developed by the manufacturer of Exubera to assess novel forms of insulin delivery such as inhaled insulin (Cappelleri et al. 2000) and was used in phase II studies (Gerber et al. 2001; Cappelleri et al. 2002). The self-administered Diabetes Quality of Life and Treatment Satisfaction Questionnaire was independently developed by Phase V Technologies and was used for all phase III studies.

A pooled analysis of the patient satisfaction data from the two 12-week parent studies in patients with type 1 diabetes $(n=70)$ or type 2 diabetes $(n=51)$ receiving Exubera or subcutaneous insulin and 1-year extension studies was performed (Rosenstock et al. 2004). Of the patients who received Exubera, $85 \%$ (51 of 60) chose to continue treatment compared with $21 \%$ (13 of 61 ) of patients receiving subcutaneous insulin. In addition, 75\% (46 of 61) of patients switched from subcutaneous insulin to Exubera compared with 13\% (8 of 60) switching from Exubera to subcutaneous insulin. At 1 year, greater improvements in patient satisfaction were observed in the Exubera group compared with the subcutaneous group for overall satisfaction $(37.9 \%$ vs $3.1 \% ; P<0.01)$ and ease of use $(43.2 \%$ vs $-0.9 \% ; P<0.01)$. However, it should be noted that the sample size at 1 year was greater for the Exubera group compared with the subcutaneous insulin group (95 patients vs 17 patients, respectively) because most of the patients originally in the subcutaneous insulin group switched to Exubera therapy during the study. Patients who switched from inhaled insulin to subcutaneous insulin showed a trend towards worsening satisfaction scores.

In addition, a study of theoretical treatment choices in 779 patients with type 2 diabetes failing to achieve target glycemic control on diet and/or oral antidiabetic therapy demonstrated that patients offered insulin as a treatment option significantly increased the proportion of patients who would theoretically choose insulin (Freemantle et al. 2005).

\section{Hypoglycemia}

Overall evidence indicates that the total number of hypoglycemic episodes with inhaled insulin and subcutaneous insulin is similar, with no increase in the incidence or severity.

Two 6-month studies demonstrated that the risk of overall hypoglycemia was lower in the Exubera group compared with the subcutaneous insulin group for patients with type 1 diabetes (8.6 vs 9 events/subject month; risk ratio 0.96) (Quattrin et al. 2004) and type 2 diabetes (1.4 vs 1.57 events/subject month; risk ratio 0.89) (Hollander et al. 2004). One 3-month study in patients with type 2 diabetes reported a higher rate of hypoglycemic epidodes with Exubera (1.3 events/patient-month) which was not surprising as Exubera was compared with oral antidiabetic therapy alone (0.1 events/patient-month) (Rosenstock 2002). However, a 3-month study in patients with type 1 diabetes reported a higher rate of hypoglycemia with Exubera (6.8 events/subject-month) compared with subcutaneous shortacting insulin (5.5 events/subject-month) (Dumas et al. 2005a). The incidence of severe hypoglycemic events was low and not significantly different in patients receiving either Exubera or subcutaneous insulin in patients with type 1 diabetes (5.5 events/100 subject months vs 4.7 events/100 subject months) (Quattrin et al. 2004) or in patients with type 2 diabetes (0.5 events/100 subject months vs 0.1 events $/ 100$ subject months, respectively) (Hollander et al. 2004).

\section{Weight gain}

Insulin therapy is often associated with weight gain, particularly in patients with type 2 diabetes. Two 6-month studies have reported that treatment with Exubera was not associated with a significant weight gain (Hollander et al. 2004; Quattrin et al. 2004). In patients with type 2 diabetes treated with Exubera, mean body weight after 24 weeks remained stable at $90.5 \mathrm{~kg}$, compared with a mean increase of $1.4 \mathrm{~kg}$ to $90.6 \mathrm{~kg}$ in body weight in the subcutaneous treatment group by week 24 (Hollander et al. 2004). Similar results occurred in patients with type 1 diabetes, with a smaller increase in body weight at week 24 in Exubera-treated patients compared with those receiving subcutaneous insulin $(0.9 \mathrm{~kg}$ vs $1.5 \mathrm{~kg})$ (Quattrin et al. 2004).

\section{Tolerability}

Level 2 evidence from two RCTs in patients with type 1 diabetes or type 2 diabetes has demonstrated that Exubera is well tolerated (Hollander et al. 2004; Quattrin et al. 2004). In these two studies, adverse events were comparable between treatment groups. Individuals treated with Exubera may develop an increase in serum insulin antibody levels, although these levels were not associated with a significant clinical change (Heise et al. 2004a,b; Fineberg et al. 2005). A meta analysis of insulin antibody data from Exubera trials demonstrated that there were no correlations between antibody binding and glycemic control, insulin dose requirements, hypoglycemic events, or pulmonary function (Fineberg et al. 2005). Furthermore, a 24-week study in patients with type 1 diabetes and results from three phase III trials in 
Table 7 | Level 2 evidence demonstrating patient satisfaction and quality of life ratings in patients treated with Exubera compared with subcutaneous insulin or oral antidiabetic agents

\begin{tabular}{|c|c|c|}
\hline Reference & Treatment group & Study design \\
\hline \multicolumn{3}{|c|}{ Type 1 diabetes } \\
\hline $\begin{array}{l}\text { Gerber et al. } \\
2001\end{array}$ & $\begin{array}{l}\text { Exubera (premeal) plus bedtime } \\
\text { dose of ultralente }(n=35) \\
\text { s.c. insulin }(n=34)\end{array}$ & $\begin{array}{l}\text { Open label; } 12 \text { weeks; PSIT } \\
\text { questionnaire at baseline and } \\
\text { week } 12\end{array}$ \\
\hline
\end{tabular}

Quattrin et al. Exubera (premeal) plus bedtime 2004;

Testa et al.

2001a;

Su et al. 2002

Testa et al. Exubera (premeal) plus NPH

$2001 b$ insulin twice daily $(n=162)$

Regular insulin (premeal) plus $\mathrm{NPH}$ insulin twice daily $(\mathrm{n}=165)$

\section{Type 2 diabetes}

Cappelleri et al. Exubera (premeal) plus bedtime 2002 dose of ultralente $(n=26)$

s.c. insulin $(n=25)$

Simonson et al. Exubera (premeal) monotherapy 2001

Remain on current oral antidiabetic

Exubera (premeal) plus current oral antidiabetic

Testa et al. 2004a,b

Exubera (premeal) $(\mathrm{n}=222)$

Metformin $(n=201)$

Simonson et al. Exubera (premeal) $(n=239)$

2004; Testa et al. Glibenclamide $(n=231)$

$2004 c$

Hollander et al. Exubera (premeal) plus bedtime 2004; Testa et al. dose of ultralente $(n=149)$ 2002 s.c. insulin $(n=150)$
Open label; parallel group; 24 weeks; self-administered Diabetes QOL and Treatment Satisfaction Questionnaire at weeks -4, $-1,6$, 12,20 , and 24

QOL and satisfaction questionnaire completed at baseline and 6, 12, 20 , and 24 weeks

Open label; 12 weeks; PSIT questionnaire

309 patients suboptimally controlled on a sulfonylurea plus either metformin or a thiazolidinedione

Patient satisfaction questionnaires completed at baseline and 6 and 12 weeks after randomization

24 weeks; patients poorly controlled on sulfonylurea; randomization stratified according to baseline $\mathrm{HbA}_{1 \mathrm{c}}$ levels (low=8-9.5\%; high=>9.5-12\%); self-administered questionnaires were completed at baseline (week 0) and at weeks 10 , 18,24 , and exit

24 weeks; patients poorly controlled on metformin monotherapy; randomization stratified according to baseline $\mathrm{HbA}_{1 \mathrm{c}}$ levels (low=8-9.5\%; high=>9.5-12\%); selfadministered questionnaires were completed at baseline (week 0 ) and at weeks 10, 18, 24, and exit

Open label; parallel group; 24 weeks; self-administered Diabetes QOL and Treatment Satisfaction Questionnaire at baseline and weeks $6,12,20$, and 24
Outcomes

Overall satisfaction was significantly greater with Exubera than with s.c. insulin $(35.1 \%$ vs $10.6 \% ; P<0.01)$

Improved convenience/ease of use with Exubera compared with s.c. insulin $(41.3 \%$ vs $11.2 \% ; P<0.01)$

Mean overall satisfaction score improved significantly for the Exubera group $(P<0.001)$ and decreased significantly with s.c. insulin $(P<0.05)$ (no scores given)

Overall QOL scale showed more favorable improvements for the Exubera group versus the s.c. insulin group $(P<0.05)$

Overall satisfaction score improved substantially more for Exubera (from 62.1 to 74.5 ) compared with regular insulin (from 62.8 to 64.3) $(P<0.0001)$

The overall QOL scale and subscales of behavioral and emotional control, general and hyperglycemic symptom distress, overall cognition, mental acuity, and awareness improved more favorably with Exubera compared with regular insulin (all $P<0.01-0.05$ )

Overall satisfaction was significantly greater with Exubera than with s.c. insulin $(31 \%$ vs $13 \% ; P<0.05)$

Improvements in overall satisfaction were positively correlated with improvements in $\mathrm{HbA}_{1 \mathrm{c}}(\mathrm{r}=0.30 ; P<0.05)$

Proportion of patients receiving Exubera monotherapy or Exubera in combination with oral antidiabetics who preferred the inhaler to their previous combination of oral antidiabetic agents for better glucose control (92\%), ease of dose adjustment $(79 \%)$, overall preference (74\%), feeling better about themselves (74\%)

Patients preferred oral agents for use in public (81\%), convenience $(69 \%)$, ease $(63 \%)$, and flexibility $(59 \%)$

Improvements in $\mathrm{HbA}_{1 \mathrm{c}}$ were positively correlated with improvements in overall satisfaction $(r=0.254 ; P<0.0001)$

Overall QOL improved similarly for Exubera $(0.24 \pm 0.09, P=0.01)$ and metformin $(0.21 \pm 0.11, P=0.06)$

Overall satisfaction (scaled 1-100) substantially improved for both Exubera (from 62.1 to $76.1, P=0.0001$ ) and metformin (from 63.1 to 74.1, $P=0.0001)$

High $\mathrm{HbA}_{1 \mathrm{c}}$ stratum: overall satisfaction was $42 \%$ greater for Exubera (from 60.2 to 77.1 ) than metformin (from 61.2 to 73.2 ) $(P=0.02)$

High $\mathrm{HbA}_{1 \mathrm{c}}$ stratum: overall QOL score more favorable for Exubera $(468 \pm 5)$ vs glibenclamide $(454 \pm 5)(P=0.04)$

Low $\mathrm{HbA}_{1 \mathrm{c}}$ stratum: no significant difference in overall QOL score between treatment groups (Exubera $457 \pm 4$ vs glibenclamide $467 \pm 5$; $P=0.08$ )

Similar improvements in treatment satisfaction for both treatment groups

Improvements in $\mathrm{HbA}_{1 \mathrm{c}}$ were positively correlated with improvements in general perceived health $(r=0.11 ; P=0.03)$, general health status $(r=0.12 ; P=0.014)$, and convenience $(r=0.15 ; P=0.003)$

Mean overall satisfaction score improved significantly for the Exubera group $(P<0.0001)$ and worsened slightly with s.c. insulin (no scores given)

Overall QOL scale showed more favorable improvements for the Exubera group versus the s.c. insulin group $(P<0.05)$

PSIT, Patient Satisfaction with Insulin Therapy Questionnaire; QOL, quality of life; s.c., subcutaneous. 
patients with type 2 diabetes over a 2-year period provided further evidence that the antibody response did not correlate with pulmonary function changes or changes in glycemic control (Cefalu et al. 2005; Dumas et al. 2005b).

There have been some concerns regarding the safety of inhaled preparations and whether they compromise lung capacity or damage lung tissue with long-term use.

Mild to moderate cough was more frequent in the inhaled insulin group $(21-30.9 \%$ of Exubera-treated patients vs $2-7.8 \%$ of subcutaneous insulin-treated patients) and decreased with increased exposure. Mean changes in pulmonary function were comparable between patients treated with subcutaneous insulin and Exubera-treated patients (Hollander et al. 2004; Quattrin et al. 2004) except for a greater decrease in carbon monoxide diffusing capacity $\left(\mathrm{DL}_{\mathrm{co}}\right)$ in the Exubera group in patients with type 1 diabetes (Quattrin et al. 2004). This decrease was not associated with any significant clinical or laboratory change.

Evidence in abstract form is available from open-label, 24-week studies which were extended with the objective of assessing pulmonary safety after long-term use of Exubera. A pooled analysis of two 1-year open-label studies involving 627 patients with type 2 diabetes showed that patients who added Exubera to their treatment regimen experienced no clinically important effect on pulmonary function compared with patients treated with oral agents alone (Barnett 2004). This study was further extended to 104 weeks and demonstrated that the treatment group differences in pulmonary function as assessed by forced expiratory volume in $1 \mathrm{~s}\left(\mathrm{FEV}_{1}\right)$ and $\mathrm{DL}_{\mathrm{co}}$ were small, not clinically relevant, and did not progress over the 2-year study period (Dreyer 2004). Furthermore, the treatment differences in pulmonary function reversed after discontinuation of Exubera during the washout phase (week +12 after 104 weeks of therapy) (Dreyer 2004). An additional analysis of 4-year Exubera data further supported these findings in patients with type 1 or type 2 diabetes (Skyler 2004a,b).

\section{Resource utilization}

There is no published evidence of the cost effectiveness of Exubera, and no decision has yet been reached on its unit cost. Greater amounts of inhaled insulin are required to produce similar efficacy to injectable formulations because of the reduced bioavailability by this route. Therefore, acquisition costs may be higher for all inhaled insulin delivery systems due to the amount of "wastage." However, it is important to consider the relatively small contribution drug therapy makes to the overall cost of managing diabetes, and the proportionately greater costs of illness and its complications that may be offset if the disease is managed effectively.

Complications of diabetes such as blindness, heart disease, and kidney failure place a huge burden on healthcare services. The IDF estimate that diabetes accounts for between 5 and $10 \%$ of a nation's health budget. Moreover, the European Cost Of Diabetes in Europe - type 2 (CODE-2) study estimated that three times the healthcare resources are spent on treating diabetes complications compared with that spent on controlling diabetes before the onset of complications. This study estimated that the average yearly cost per patient was €2834. Of these costs, hospitalizations accounted for the greatest proportion (55\%, range 30-65\%) totalling $€ 15.9$ billion. In contrast, drug costs for managing type 2 diabetes were relatively low, with antidiabetic drugs and insulin accounting for only $7 \%$ of the total healthcare costs for type 2 diabetes (Jonsson 2002). Therefore, the human and economic costs of diabetes could be reduced by preventing the onset of these complications.

There is strong evidence that good glycemic control with intensive insulin therapy can substantially reduce the risk of and slow the progression of these complications (DCCT 1993; Ohkubo et al. 1995; UKPDS 1998b). Studies have shown that $\mathrm{HbA}_{1 \mathrm{c}}$ levels are directly linked to healthcare costs with even a $1 \%$ increase in $\mathrm{HbA}_{1 \mathrm{c}}$ levels increasing healthcare costs (Gilmer et al. 1997; Gray et al. 2000; Clarke et al. 2001). Therefore, it would be expected that noncompliance with insulin therapy would lead to poor glycemic control and thereby have an adverse impact on the development of diabetes complications and increase healthcare costs. This highlights the need for alternative therapies for the treatment of diabetes which improve patient adherence and hence glycemic control. Controlling blood glucose should have a beneficial effect on costs, but in order to determine Exubera's place in therapy, comparisons with other inhaled devices and additional patient preference data are needed.

\section{Patient group/population}

Level 2 evidence demonstrates the safety and efficacy of Exubera in patients with type 1 and type 2 diabetes who are otherwise healthy, suggesting that it could have a role in the general treatment of patients with uncomplicated disease. Evidence with inhaled insulin is limited in patients with concomitant diseases. Key factors which may influence the efficiency of inhaled insulin delivery include the patients' age (i.e. pediatric and elderly), ability to operate the device, smoking, asthma, exercise, and the presence of lung disease such as chronic obstructive pulmonary disease or chronic bronchitis. Limited evidence from a small number of studies with AERx insulin Diabetes Management System (iDMS) in smokers, patients with asthma, and the elderly is available, some of which may be applicable to Exubera. However, stronger evidence is required to clearly establish the efficacy and safety of Exubera in these patient groups.

\section{Smoking}

Smoking appears to greatly enhance insulin absorption by increasing the permeability of the alveolar-capillary barrier (Jones et al. 1980). In a randomized crossover study 27 nondiabetic smokers and 16 nonsmokers received relatively low single doses of $33.8 \mathrm{IU}$ inhaled insulin AERx iDMS (Himmelmann et al. 2003). Absorption of inhaled insulin was significantly greater in smokers with a higher area under the curve $\left(A \cup C_{(0-6 h)}\right), C_{\max }$ and $t_{\max }$ 
The effects of smoking cessation and resumption on the absorption of Exubera have also been investigated. Two randomized, crossover studies demonstrated that Exubera absorption was two- to three-fold greater in smokers compared with nonsmokers prior to cessation of smoking (Sha et al. 2002; Becker et al. 2003). These studies also showed that the absorption of Exubera decreases during nonsmoking periods and subsequently increases once smoking is resumed (Sha et al. 2002; Becker et al. 2003).

\section{Asthma}

Individuals with asthma have altered pulmonary function. Therefore, the absorption of inhaled insulin may be affected and the airways of asthmatics may develop a hypersensitivity reaction. An open-label, parallel-group study examined the effects of inhaled insulin (AERx iDMS) on pulmonary function in 17 asthmatic nondiabetic subjects compared with 28 healthy individuals (Henry et al. 2003a). The pharmacokinetics and pharmacodynamics of inhaled insulin were also determined. Asthmatic subjects absorbed less insulin than healthy subjects [insulin $\mathrm{AUC}_{(0-360 \mathrm{~min})} 1.45 \times 10^{6} \mathrm{pmol} / \mathrm{min}$ per $\mathrm{kg}$ healthy volunteers vs $1.07 \times 10^{6} \mathrm{pmol} / \mathrm{min}$ per $\mathrm{kg}$ asthmatic patients $(P=0.013)]$. These results suggest that diabetic patients with asthma may need to inhale more insulin than patients with normal respiratory function in order to achieve similar glycemic control.

\section{Age}

Convenience and ease of use of the Exubera inhaler should be studied in elderly patients with diabetes because the device may have limitations with regards to dexterity, and elderly patients' ability to breathe deeply may be compromised.

It is also necessary to conduct pharmacokinetic studies with Exubera in elderly patients with diabetes to determine the effect of lung aging on the bioavailability of inhaled insulin (Belmin \& Valensi 2003). An open-label trial investigating the pharmacokinetics and pharmacodynamics of inhaled insulin (AERx iDMS) demonstrated that the intrasubject variability in elderly patients ( $\geq 65$ years) was similar to that for young patients (18-45 years) with a comparable pharmacokinetic profile (Henry et al. 2003b). However, glucose reduction was significantly less in elderly patients and the authors suggested that elderly diabetic patients may need to inhale more insulin to achieve similar glycemic control.

Furthermore, a trial comparing the pharmacokinetics and pharmacodynamics of Exubera with subcutaneous insulin in elderly patients (mean age 72 years) demonstrated that Exubera is absorbed more rapidly and has a similar or better intrasubject variability than subcutaneous insulin (Henry et al. 2003c).

There are insufficient studies to be able to judge utility in elderly patients. Further well-designed studies are required to investigate the effects on insulin absorption and hence the dosage requirements in these patient groups.

\section{Outcomes summary}

Glycemic control with Exubera inhaled insulin before meals in conjunction with an injected basal insulin is comparable to that in patients receiving multiple daily injections, with no difference in the incidence of hypoglycemia or weight gain.

A major benefit of Exubera in comparison to subcutaneous insulin appears to be the improvement in patient treatment satisfaction which is presumed to be related to its ease of use, leading to better adherence to treatment. However, there is limited evidence to show the effects of long-term Exubera treatment on pulmonary function.

In summary, current evidence suggests that Exubera is an alternative to short-acting subcutaneous insulin therapy providing a further choice for the treatment of patients with type 1 or type 2 diabetes. However, the availability of inhaled insulin would not mean an end to injections, as patients with type 1 diabetes, and many patients with type 2 diabetes, would still require daily injections of basal insulin. Exubera may lead to earlier introduction of insulin therapy in type 2 diabetes based on improved patient acceptance and improved glycemic control and may eliminate the need for mealtime insulin injections in diabetic patients requiring insulin therapy. There is also limited evidence available for the efficacy and safety in patient groups with compromised lung capacity (e.g. smokers, asthmatics). The improved acceptability of Exubera translating into better diabetes control may have a substantial impact on the burden of disease. Further studies are essential to determine Exubera's place in therapy compared with other inhaled insulin delivery systems currently in development.

\section{References}

AACE (American Association of Clinical Endocrinologists). State of Diabetes in America. Available at: http://www.stateofdiabetes.com (accessed June 23, 2005).

ADA (American Diabetes Association). Insulin administration. Diabetes Care. 2004;27(Suppl. 1):S106-S109.

ADA (American Diabetes Association). National Diabetes Fact Sheet, 2005a. Available at: http://www.diabetes.org/diabetes-statistics/national-diabetes-factsheet.jsp (accessed May 5, 2005).

ADA (American Diabetes Association). Resource Guide 2005. Diabetes Forecast. 2005b;58(1).

ADA (American Diabetes Association). Standards of medical care in diabetes. Diabetes Care. 2005c;28(Suppl. 1):S4-S36.

Barlocco D. LAF-237 (Novartis). Curr Opin Invest Drugs. 2004;5:1094-1100.

Barnett $\mathrm{AH}$, for the Exubera Phase III Study Group. Efficacy and one-year pulmonary safety of inhaled insulin (Exubera) as adjunctive therapy with metformin or glibenclamide in type 2 diabetes patients poorly controlled on oral agent monotherapy. Diabetes. 2004;53(Suppl. 2):A107.

Becker RHA, Sha S, Frick AD, Piechatzek R. The effect of smoking cessation and subsequent resumption on absorption of inhaled insulin (Exubera ${ }^{\circledR}$ ). Diabetes. 2003;52(Suppl. 1):A37.

Belmin J, Valensi P. Novel drug delivery systems for insulin: clinical potential for use in the elderly. Drugs Aging. 2003;20(4):303-312.

Bergenstal R, for the Exubera Phase III Study Group. Efficacy and safety of inhaled insulin (Exubera ${ }^{\circledR}$ ) compared with rosiglitazone in type 2 diabetes patients not optimally controlled on diet and exercise: results of a 3-month, randomized, comparative trial. Diabetologia. 2003;46(Suppl. 2):A277. 
Bergenstal R. Achieving target $\mathrm{HbA}_{1 \mathrm{C}}$ in studies with inhaled insulin in type 2 diabetes. Diabetologia. 2004;47(Suppl. 1):A312.

Cappelleri JC, Gerber RA, Kourides IA, Gelfand RA. Development and factor analysis of a questionnaire to measure patient satisfaction with injected and inhaled insulin for type 1 diabetes. Diabetes Care. 2000;23(12):1799-1803.

Cappelleri JC, Gerber RA, Rosenstock J, et al. Relationship between improved patient satisfaction and improved glycemic control in patients with type 1 and type 2 diabetes mellitus treated with inhaled insulin. Diabetes. 2001;50(Suppl. 2).

Cappelleri JC, Cefalu WT, Rosenstock J, Kourides IA, Gerber RA. Treatment satisfaction in type 2 diabetes: a comparison between an inhaled insulin regimen and a subcutaneous insulin regimen. Clin Ther. 2002;24(4):552-564.

CDC (Centers for Disease Control and Prevention). National Diabetes Fact Sheet, USA, 2003. Available at:

http://www.cdc.gov/diabetes/pubs/pdf/ndfs_2003.pdf (accessed January 21, 2005).

Cefalu WT. Inhaled insulin: A proof-of-concept study. Ann Intern Med. 2001;134(9 Part 1):795.

Cefalu WT, for the Exubera Phase 3 Study Group. Mealtime rapid-acting inhaled insulin (Exubera) improves glycaemic control in patients with type 2 diabetes failing combination oral agents: A 3-month, randomised, comparative trial. Diabetologia. 2002;45:A260.

Cefalu WT. Concept, strategies, and feasibility of noninvasive insulin delivery. Diabetes Care. 2004;27(1):239-246.

Cefalu WT, Serdarevic-Pehar M, for the Exubera Phase 3 Study Group. Longterm use of Exubera in type 2 diabetes: observations on glycemic control, pulmonary function and antibody formation. Diabetes. 2005;54(Suppl. 1):Abstract 356-OR.

Clarke P, Gray A, Adler A, et al.; UKPDS Group. United Kingdom Prospective Diabetes Study. Cost-effectiveness analysis of intensive blood-glucose control with metformin in overweight patients with type II diabetes (UKPDS No. 51) Diabetologia. 2001;44(3):298-304.

Cramer JA, Okikawa J, Bellaire S, Clauson P. Compliance with inhaled insulin treatment using the AERx Idms Insulin Diabetes Management System. Diabetes Technol Ther. 2004;6:800-807.

DCCT (Diabetes Control and Complications Trial) Research Group. The effect of intensive treatment of diabetes on the development and progression of longterm complications in insulin-dependent diabetes mellitus. N Engl J Med. 1993;329(14):977-986.

DeFronzo R. Efficacy and safety of inhaled insulin (Exubera ${ }^{\circledR}$ ) compared with rosiglitazone in type 2 diabetes patients not optimally controlled on diet and exercise: Results of a 3-month, randomized, comparative trial. Diabetes. 2003;52(Suppl. 1):A38 (Abstract 162).

Dreyer M. Efficacy and two-year pulmonary safety of inhaled insulin as adjunctive therapy with metformin or glibenclamide in type 2 diabetes patients poorly controlled with oral monotherapy. Diabetologia. 2004;47(Suppl. 1):A44.

Dumas R, Krasner AS, England RD, Riese RJ, Teeter JG, for the Exubera Phase 3 Study Group. Exubera is well tolerated and achieves tight glycemic control in patients with type 1 diabetes. Diabetes. 2005a;54(Suppl. 1):Abstract 355-OR.

Dumas R, Krasner AS, England RD, Riese RJ, Teeter JG, for the Exubera Phase 3 Study Group. Immunologic response to Exubera in patients with type 1 diabetes is not associated with functional evidence of airway sensitization. Diabetes. 2005b;54(Suppl. 1):Abstract 437-P.

EDPG (European Diabetes Policy Group) (International Diabetes Federation European Region). A desktop guide to type 2 diabetes. Diabetic Med. 1999;16:716-730.

Fineberg SE, Kawabata T, Finco-Kent D, Liu C, Krasner A. Antibody response to inhaled insulin in patients with type 1 or type 2 diabetes. An analysis of initial phase II and III inhaled insulin (Exubera) trials and a two-year extension trial. $J$ Clin Endocrinol Metab. 2005;90:3287-3294.

Freemantle N, Blonde L, Duhot $\mathrm{D}$ et al. Availability of inhaled insulin promotes greater perceived acceptance of insulin therapy in patients with type 2 diabetes. Diabetes Care. 2005;28:427-428.

Gerber RA, Cappelleri JC, Kourides IA, Gelfand RA. Treatment satisfaction with inhaled insulin in patients with type 1 diabetes: a randomized controlled trial. Diabetes Care. 2001;24(9):1556-1559.
Gilmer TP, O'Connor PJ, Manning WG, et al. The cost to health plans of poor glycemic control. Diabetes Care. 1997;20:1847-1853.

Gray A, Raikou M, McGuire A, et al. Cost effectiveness of an intensive blood glucose control policy in patients with type 2 diabetes: economic analysis alongside randomised controlled trial (UKPDS 41). United Kingdom Prospective Diabetes Study Group. BMJ. 2000;320(7246):1373-1378.

Guevara-Aguirre J, Guevara M, Saavedra J, Mihic M, Modi P. Oral spray insulin in treatment of type 2 diabetes: a comparison of efficacy of the oral spray insulin (Oralin) with subcutaneous (SC) insulin injection, a proof of concept study. Diabetes Metab Res Rev. 2004a;20(6):472-478.

Guevara-Aguirre J, Guevara M, Saavedra J, Mihic M, Modi P. Beneficial effects of addition of oral spray insulin (Oralin) on insulin secretion and metabolic control in subjects with type 2 diabetes mellitus suboptimally controlled on oral hypoglycemic agents. Diabetes Technol Ther. 2004b;6(1):1-8.

Heise T, Tusek C, Stephan J-A, et al. Postprandial glucose control unaffected by insulin antibodies associated with inhaled insulin. Diabetologia. 2004a;47(Suppl. 1):A311.

Heise T, Tusek C, Stephan J-A, et al. Insulin antibodies with inhaled insulin (Exubera): no evidence for impact on postprandial glucose control. Diabetes. 2004b;53(Suppl. 2):A109.

Henry RR, Mudaliar SR, Howland WC 3rd, et al. Inhaled insulin using the AERx Insulin Diabetes Management System in healthy and asthmatic subjects. Diabetes Care. 2003a;26(3):764-769.

Henry RR, Mudaliar S, Chu N, et al. Young and elderly type 2 diabetic patients inhaling insulin with the AERx insulin diabetes management system: a pharmacokinetic and pharmacodynamic comparison. $\mathrm{J}$ Clin Pharmacol. 2003b;43(11):1228-1234.

Henry RR, Mudalier SR, Fryburg DA, et al. Within-subject variability of inhaled insulin $\left(E^{2}\right.$ ubera $\left.{ }^{\circledR}\right)$ versus subcutaneous regular insulin in elderly obese patients with type 2 diabetes mellitus. Diabetes. 2003c;52(Suppl. 1):A105.

Himmelmann A, Jendle J, Mellen A, Petersen AH, Dahl UL, Wollmer P. The impact of smoking on inhaled insulin. Diabetes Care. 2003;26(3):677-682.

Hogan P, Dall T, Nikolov P; American Diabetes Association. Economic costs of diabetes in the US in 2002. Diabetes Care. 2003;26:917-932.

Hollander PA, Blonde L, Rowe R, et al. Efficacy and safety of inhaled insulin (exubera) compared with subcutaneous insulin therapy in patients with type 2 diabetes: results of a 6-month, randomized, comparative trial. Diabetes Care. 2004;Oct;27(10):2356-2362.

IDF (International Diabetes Federation). Diabetes Facts \& Figures. Available at: http://www.idf.org/home/index.cfm?unode=3B96906B-C026-2FD387B73F80BC226 (accessed January 19, 2005).

Jones JG, Minty BD, Lawler P, Hulands G, Crawley JC, Veall N. Increased alveolar epithelial permeability in cigarette smokers. Lancet. 1980;1(8159):66-68.

Jonsson B; CODE-2 Advisory Board. Revealing the cost of Type II diabetes in Europe. Diabetologia. 2002;45(7):S5-12.

Koro CE, Bowlin SJ, Bourgeois N, Fedder DO. Glycemic control from 1988 to 2000 among U.S. adults diagnosed with type 2 diabetes: a preliminary report. Diabetes Care. 2004;27(1):17-20.

Korytkowski M. When oral agents fail: practical barriers to starting insulin. Int $J$ Obes Relat Metab Disord. 2002;26(Suppl. 3):S18-24.

Krentz AJ, Bailey CJ. Oral antidiabetic agents. Current role in type 2 diabetes mellitus. Drugs. 2005;65:385-411.

Mandal TK. Inhaled insulin for diabetes mellitus. Am J Health-Syst Pharm. 2005;62:1359-1364.

NICE (National Institute for Health and Clinical Excellence). Clinical guidelines for type 2 diabetes: Management of blood glucose. September 2002. Available at: http://www.nice.org.uk (accessed February 28, 2005).

Nielsen LL. Incretin mimetics and DPP-IV inhibitors for the treatment of type 2 diabetes. Drug Discov Today. 2005;10(10):703-710.

Ohkubo $\mathrm{Y}$, Kishikawa $\mathrm{H}$, Araki $\mathrm{E}$, et al. Intensive insulin therapy prevents the progression of diabetic microvascular complications in Japanese patients with non-insulin-dependent diabetes mellitus: a randomized prospective 6-year study. Diabetes Res Clin Pract. 1995;28:103-117. 
Owens DR, Zinman B, Bolli G. Alternative routes of insulin delivery. Diabetic Med. 2003;20:886-898.

Patton JS, Bukar JG, Eldon MA. Clinical pharmacokinetics and pharmacodynamics of inhaled insulin. Clin Pharmacokinet. 2004;43(12):781-801.

Pinhas-Hamiel O, Zeitler P. The global spread of type 2 diabetes mellitus in children and adolescents. J Pediatr. 2005;146:693-700.

Quattrin T, Belanger A, Bohannon NJ, Schwartz SL; Exubera Phase III Study Group. Efficacy and safety of inhaled insulin (Exubera) compared with subcutaneous insulin therapy in patients with type 1 diabetes: results of a 6month, randomized, comparative trial. Diabetes Care. 2004;27(11):2622-2627.

Rave K, Bott S, Heinemann L, et al. Time-action profile of inhaled insulin in comparison with subcutaneously injected insulin lispro and regular human insulin. Diabetes Care. 2005;28:1077-1082.

Rosenstock J, for the Exubera Phase III Study Group. Mealtime rapid-acting inhaled insulin (Exubera) improves glycemic control in patients with type 2 diabetes failing combination oral agents: a 3-month, randomized, comparative trial. Diabetes. 2002;51(Suppl. 2):A132.

Rosenstock J, Cappelleri JC, Bolinder B, Gerber RA. Patient satisfaction and glycemic control after 1 year with inhaled insulin (Exubera) in patients with type 1 or type 2 diabetes. Diabetes Care. 2004;27(6):1318-1323.

Royle P, Waugh N, McAuley L, McIntyre L, Thomas S. Inhaled insulin in diabetes mellitus. Art. No.:CD003890.pub2. DOI: 10.1002/14651858.CD003890.pub2. Cochrane Database of Systematic Reviews. 2003, Issue 4.

Selvin E, Marinopoulos S, Berkenblit G, et al. Meta-analysis: glycosylated hemoglobin and cardiovascular disease in diabetes mellitus. Ann Intern Med. 2004;141:421-431.

Sha S, Becker RHA, Willavize SA, et al. The effect of smoking cessation on the absorption of inhaled insulin (Exubera ${ }^{\circledR}$ ). Diabetes. 2002;51(Suppl. 2):A133.

Simonson DC, Hayes JF, Turner RR, Testa MA. Treatment satisfaction and preferences in type 2 diabetes: A randomized trial of oral agents vs. inhaled insulin. Diabetes. 2001;50(Suppl. 2):A131.

Simonson DC, Turner RR, Hayes JF, Scranton RE, Testa MA. Improving quality of life in type 2 diabetes when Exubera is added after failure on metformin: a multicenter, international trial. Diabetologia. 2004;47(Suppl. 1):A311.

Skyler JS, Cefalu WT, Kourides IA et al. Efficacy of inhaled human insulin in type 1 diabetes mellitus: A randomized proof-of-concept study. Lancet. 2001;357:331-335.

Skyler JS. Long-term, sustained efficacy, and safety of inhaled insulin after 4 years of continuous therapy. Diabetologia. 2004a;47(Suppl. 1):A311.

Skyler J, for the Exubera Phase II study group. Sustained long-term efficacy and safety of inhaled insulin during 4 years of continuous therapy. Diabetes. 2004b;53(Suppl. 2):A115.
Skyler JS, Weinstock RS, Raskin P, et al. Use of inhaled insulin in a basal/bolus insulin regimen in subjects with type 1 diabetes: A 6-month, randomized, comparative trial. Diabetes Care. 2005:28:1630-1635.

Steiner S, Pfutzner A, Wilson BR, et al. Technosphere/insulin-proof of concept study with a new insulin formulation for pulmonary delivery. Exp Clin Endocrinol Diabetes. 2002;110:17-21.

Su M, Testa MA, Turner RR, et al. The relationship between regimen burden and psychological well-being in persons with type 1 diabetes: inhaled vs injectable insulin. Diabetes. 2002;51(Suppl. 2):A448-A449.

Testa MA, Turner RR, Hayes JF, et al. Patient satisfaction and quality of life in type 1 diabetes: A randomized trial of injectable vs. inhaled insulin. Diabetes. 2001a;50(Suppl. 2):A45.

Testa MA, Turner RR, Hayes JF, et al. Intensive therapy and patient satisfaction in type 1 diabetes: A randomized trial of injected vs inhaled insulin. Diabetologia. 2001b;44(Suppl. 1):A4.

Testa MA, Turner RR, Hayes JF, et al. Patient satisfaction with insulin therapy in type 2 diabetes: A randomized trial of injectable vs inhaled insulin. Diabetes. 2002;51(Suppl. 2):A135.

Testa MA, Turner RR, Hayes JF, Scranton RE, Simonsen DC. An international trial of sulfonylurea plus either metformin or Exubera: impact on quality of life and treatment satisfaction. Diabetologia. 2004a;47(Suppl. 1):A5.

Testa MA, Hayes JF, Turner RR, Simonsen DC. Satisfaction and quality of life with sulfonylurea plus either metformin or Exubera: An international randomized Phase 3 trial. Diabetes. 2004b;53(Suppl. 2):A115.

Testa MA, Hayes JF, Turner RR, Simonsen DC. Quality of life improvements in type 2 diabetes when Exubera is added after failure on metformin monotherapy: An international randomized Phase 3 trial. Diabetes. 2004c;53(Suppl. 2):A437.

UKPDS (UK Prospective Diabetes Study) Group. Effect of intensive bloodglucose control with metformin on complications in overweight patients with type 2 diabetes (UKPDS 34). Lancet. 1998a;352:854-865.

UKPDS (UK Prospective Diabetes Study) Group. Intensive blood-glucose control with sulphonylureas or insulin compared with conventional treatment and risk of complications in patients with type 2 diabetes (UKPDS 33). UK Prospective Diabetes Study (UKPDS) Group. Lancet. 1998b;352:837-853.

Weiss SR, Cheng SL, Kourides IA, Gelfand RA, Landschulz WH; Inhaled Insulin Phase II Study Group. Inhaled insulin provides improved glycemic control in patients with type 2 diabetes mellitus inadequately controlled with oral agents: a randomized controlled trial. Arch Intern Med. 2003;163:2277-2282.

Correspondence: Louise Profit, Core Medical Publishing, Mere House, Brook Street, Knutsford, Cheshire WA16 8GP, UK or at editor@coreevidence.com 